Ida Maryati : The Application of "Roy Adaptation" Theory Model In Women

\title{
THE APPLICATION OF "ROY ADAPTATION" THEORY MODEL IN WOMEN WITH EARLY STAGE OF CERVICAL CANCER: A STUDY CASE
}

\author{
Ida Maryati ${ }^{1}$, Sukmawati ${ }^{1}$, Lilis Mamuroh ${ }^{1}$ \\ ${ }^{1,2,3}$ Faculty of Nursing, Universitas Padjadjaran, Bandung, Indonesia \\ Correspondence: ida.maryati@unpad.ac.id
}

\begin{abstract}
Women who diagnosed with cervical cancer face complex problems including physiological, psychological, social, and spiritual problems. Women are required to adapt to these complex problems. Nurses as part of health care providers have responsibilities to help clients in dealing with their conditions. Another role of nurses is to assist clients to meet their basic needs. Nurses provide nursing care using a variety of nursing theories so that the nursing care provided is optimal. One of the nursing theory is Roy's adaptation model, this model is one of theory as a foundation in providing nursing care. The aimed of the theory application was to apply the Roy theory, and it also expected that women with early-stage cervical cancer could adapt to their conditions. Method: The design of this study was a case study approach of five cases of a cervix. Roy's adaptation model applied effectively to early-stage of cervical cancer clients, as a result, clients adapt to changes that occur including physiologically, psychologically, socially, and spiritually. Roy's adaptation model would be more effective if it applies in combination with other concepts, especially theories about self-concept and social support to the nursing care provided would be more optimal.
\end{abstract}

Keywords: cervical cancer, early stage, Roy's adaptation model

\section{INTRODUCTION}

In Indonesia, cervical cancer is the second largest of deathly disease that threatening women after breast cancer (Ministry of Health, 2015). Various problems faced by cervical cancer clients, including physiological, psychological, social, and spiritual problems. The cervical cancer clients are expected to adapt to these complex problems. Nurses have a role to help clients' adaptation to their conditions, as one of the roles of nurses is to fulfill patients' basic needs. Nurses would combine various concept models in nursing care so that the nursing care provided is comprehensive.

Physiological changes in women with cervical cancer include bleeding, smelling vaginal discharge, treatment effects, and the loss of reproductive organs such as the vagina, cervix, and uterus. Roy's adaptation model is a nursing model that is suitable to be applied to the nursing care of early-stage cervical cancer clients because the impact of cervical cancer must be 
Ida Maryati : The Application of "Roy Adaptation" Theory Model In Women

adopted by the patient and family. Another impact caused by early cervical cancer is a change in the lives of clients and families. Clients and families must be able to adapt to the changes that occur. The inability to adapt is at risk of causing adaptive mall behavior.

One of the nursing interventions that would help the client to adapt to the changes is providing psychosocial support. Psychosocial support is a mechanism to protect someone from the effects of stress (Kaplan \& Sudock, 2011). According to Li, Chen, Chang, Chou, and Chen (2015) psychosocial support is obtained from families, health care workers, the environment such as the community, the foundation or the association. The family, especially the husband, is the closest person and has a close emotional bond with the client and has a very big influence in helping the client to adapt to the illness he experiences. Psychosocial support can be in the form of emotional support, information, material, or energy.

Nurses as nursing care providers help clients and families to develop the care management plans. Nurses need to know the client's self-concept to help clients adapt to the changes experienced so that the quality of life of clients would be optimal. By focusing on the application of Roy's adaptation concepts and theories, the nursing care provided is more effective. This theory of application is a comprehensive theory. The aim of the theory application was to apply the Roy theory, and it also expected that women with early-stage cervical cancer could adapt to their conditions.

\section{METHODS}

This case study involved five women diagnosed with early-stage cervical cancer in a national referral hospital. According to Susilo Rahardjo \& Gudnanto (2011: 250), a case study is a design to understand an event carried out integratively and comprehensively in order to obtain a deep 
Ida Maryati : The Application of "Roy Adaptation" Theory Model In Women

understanding of the case. Case studies applied in five stages which consist of assessment, nursing diagnosis, nursing plan, implementation, and evaluation. The theoretical model that applies was Roy's adaptation model. The assessment was divided into two stages, the first stage includes physiological assessment, role function, self-concept, and interdependence. The second stage includes focal, contextual and residual stimulus studies. When the assessment phase completed, and then we created a nursing diagnosis and also nursing plan. The next steps were implementation and evaluation.

\section{RESULT}

This section presents the study findings including the characteristics of respondents and the nursing care plan of 5 five cases of cervical cancer.

Characteristic of respondents

Case 1

Mrs. H, 38 years old, married, the age of marriage was 20 years old, a Moslem, civil servants, Javanese, and final education was a diploma. She has one child, has used oral contraception for 3 years, and has a history of cousins who died of cervical cancer. She has diagnosed with stage IIA cervical cancer. She was worried about the conditions that happened to her. After the uterus surgery, she felt to be imperfect as a wife and woman. She was worried that her husband would love another woman.

Case 2

Mrs. N, 36 years old, a widow from the second marriage, the age of marriage was 18 years old, a Moslem, Betawi tribe, attended junior high school, and private employment. She has one child, has used oral contraception for 5 years, and has a history of smoking from high school. 
Ida Maryati : The Application of "Roy Adaptation" Theory Model In Women

In a day she spent 12 cigarettes. She was referred to hospital because of vaginal bleeding. She lost her weight about $10 \mathrm{~kg}$ in 8 months. She perceived herself as an unlucky person because of this illness. She was divorced by her husband because of her illness.

Case 3

Mrs. S, 48 years old, married, the age of marriage was 20 years old, a housewife, a Moslem, Sundanese tribe, attended elementary school education. She has one child, has used oral contraception for 4 years, and her mother died because of cervical cancer. She is diagnosed with stage IIA of cervical cancer. She was worried about the conditions especially the impact of the uterus surgery. She was worried that she could not carry out her roles as a wife including having sex with her husband.

\section{Case 4}

Mrs. K, 46 years old, married, the age of marriage was 18 years old, first marriage, Christianity, Batak tribe, housewife, attended senior high school. She has five children and has used oral contraception for 6 years. She is diagnosed with stage IIA of cervical cancer. The client underwent a radical hysterectomy surgery, she feels she is a lucky wife because she has a faithful husband. However, she felt guilty because she could not carry out her roles as a mother and wife perfectly. Initially, she was a proud wife as she had an ideal weight and able to pregnant four children. However, since she had diagnosed with cervical cancer she felt sad and lost her pride.

\section{Case 5}

Mrs. L, 48 years old, married, the age of marriage was 20 years old, Christianity, Batak tribe, a housewife, attended the senior high school education. She has three children and has used oral 
Ida Maryati : The Application of "Roy Adaptation" Theory Model In Women

contraception for more than 7 years. She is diagnosed with stage IB cervical cancer and referred to the hospital because of vaginal bleeding.

The first phase of the assessment

According to Roy's theory, the first phase of the study includes physiological adaptation consisting of oxygenation, nutrition, protection, fluid and electrolytes, neurological functions and endocrine function (Roy, 2008).

\section{Physiological Adaptation}

The majority of clients referred to the hospital because of vaginal bleeding. Clients had a smelly vaginal discharge and had postcoital bleeding. The general assessment found that clients did not have problems with oxygenation, nutrition, protection, fluids and electrolytes, neurological functions and endocrine functions.

\section{Self-concept}

The self-concept assessment found that clients felt anxious about the results of a doctor's examination which stated that the prognosis of her disease is bad and surgery must be done immediately. Several clients said she was not sure of the decision that they had made about surgery as client's cousin had died after breast surgery. Several clients argued that cancer he suffered was like a curse from God for their family because his mother and cousin died of the same disease. Several clients imagined that death is close to them, and it disturbed their night sleep. Several clients revealed that they feel guilty because they are the burden for their family, and could not help their family, they asked why they suffered from cancer as they never did any immoral behavior in society. 
Adaptation of the role functions

Clients said that before suffered from cancer they were active in the communities, and they did not want to do the community activities since they suffered from cancer. They perceived that they are dirty and embarrassing their family. Clients said they could no longer carry out their role as a wife because there were post-coital bleeding, and they felt afraid to have physical contact with their husbands. They felt guilty to the husband when they could not have sex.

Adaptasi interdepend

Clients have good relationships with children and husbands. The husband accompanied her in the hospital. Her child took turns with her husband to accompany her in the hospital. During the illness, there were no relatives visiting her because of the far distance to the hospital from the hometown.

\section{The second step of the assessment}

\section{The focal stimuli}

The client looks worried, and the extremities feel cold. The client sees himself as a lucky person because she has a good child and husband, but this disease makes she feels guilty because she cannot act as a wife optimally. Before getting sick the client was so proud of his body because she has everything. However, the surgical plan to remove the uterus had impacted their pride.

\section{The contextual stimuli}

The client complained that there was vaginal bleeding since a year ago, colored fresh, sometimes brownish red, and odorless. In a day the client changed the pads 3-4 times. The client 
Ida Maryati : The Application of "Roy Adaptation" Theory Model In Women

said she had leucorrhoea since two years ago, but she considered it was a normal thing so she did not visit health services. Several months ago the vaginal discharge began it was yellow, and she had postcoital bleeding since a year ago. Clients experienced pain during intercourse. The laboratory found the client had positive indications of cervical cancer.

\section{The residual stimuli}

The client said she had vaginal bleeding since a year ago. Blood characteristic was fresh red, sometimes brownish red, and no smell. In a day the client changed the pads 3-4 times. She had leucorrhoea since two years ago, however, she considered it was a normal condition so she did not search for the treat. A few months ago the client had vaginal discharge with characteristics were runny, and yellow. Since one year ago there was postcoital bleeding. Her mother passed away because of vaginal bleeding. She perceived that maybe her mother had cancer like her. In addition, her cousins also died at 40 years of age due to breast cancer.

\section{Nursing diagnosis and Nursing Care Plans}

Psychosocial diagnoses in cervical cancer clients include anxiety related to disease processes, changes in self-concept: wife's roles related to disease processes, changes in family processes related to crisis situations, and spiritual distress associated with the disease process.

\section{Implementation and Evaluation}

The aim of nursing implementation was to changing or manipulating focal, contextual, and residual stimuli. This nursing care is evaluated by evaluating the adaptive behavior of the 
Ida Maryati : The Application of "Roy Adaptation" Theory Model In Women

client. After getting nursing care with Roy's adaptation model, early-stage cervical cancer clients can adapt both physically, psychologically, socially, and spiritually.

\section{DISCUSSION}

The characteristics of the respondents indicated that all respondents were in reproductive age. The risk factors of respondents were early marriage, number of marriages, parity, oral contraceptive history of family members with cervical cancer and a history of smoking. The age of marriage of the respondents was mostly 18 years, that age is in accordance with the marriage law in Indonesia. The highest number of children was 5 children and there were respondents using oral contraception for more than seven years. Two respondents had a family history of cervical cancer and one response had a history of smoking. Characteristics of respondents in this study were matched with risk factors in cervical cancer (Durham \& Chapman, 2014).

Roy's adaptation model is a nursing model that is very suitable to be applied to clients with early-stage cervical cancer. The impact of this application changed the lives of clients and families so that they are required to adapt to these changes. Failure in adapting to the changes may lead to maladaptive mall behavior (Roy, 2008).

Problems that arise in the five cases were varied depending on the patient conditions and patient's social support. Applying Roy's adaptation model was useful to help all clients in adapting and accepting effects that occur due to treatment. Nurses should be able to provide comprehensive care through the application of theories and nursing models so that the care provided can be optimal. The application of Roy's adaptation model theory strongly supports nursing care provided by nurses. Women with cervical cancer experience psychological disorders, such as anger, depression, fear of death, loss of self-confidence, impaired role, and 
Ida Maryati : The Application of "Roy Adaptation" Theory Model In Women

loss of sexual desire (Kaplan \& Sudock, 2011). However, if there are optimal support and mature personality, the patient is able to adjust to the changes that occur and be able to behave normally even though the physical condition is no longer perfect ( $\mathrm{Li}$, Chen, Chang, Chou, and Chen, 2015).

In early-stage cervical cancer, one of the procedures is surgery to take all or part of the vaginal organs, cervix, and uterus (Durham \& Chapman, 2014). These actions affect the role and function of the client's reproductive system. Bhattacharjee (2013) found that clients with cervical cancer experience impaired body image in connection with the disease process and the effects of treatment. This is supported by the statement of Bhattacharjee (2013) which states that changes in the appearance and function of the body cause disruption of self-esteem resulting in changes in self-concept. Self-concepts that negatively affect mental health conditions and will affect the success of treatment.

Roy's adaptation model is a model of nursing care that is suitable for application to clients with early-stage cervical cancer. Roy's adaptation model helps patients and families to adapt to their health conditions (Roy, 2008). One of the efforts made is to provide psychosocial support. Through psychosocial support, clients would be protected from the effects of bad stress. Psychosocial support is obtained from families, health workers, the environment, the community, and social organizations. Support provided can be in the form of emotional support, information, material, and energy (Kaplan \& Sudock, 2011; Li Chen, Chang, Chou, and Chen, 2015).

In applying this model in five cases, the first and second stages of the study were carried out. Before conducting the assessment, the nurse established mutual trust with the client. The condition of the five cases was generally not severe, as a result during the assessment processes clients and nurses could collaborate well. When assessing clients' self-concept and role 
Ida Maryati : The Application of "Roy Adaptation" Theory Model In Women

functions, there was a specific skill of the nurse to gather information from the client because these areas are sensitive and privacy for clients.

The results of the first and second stages of the assessment are then enforced in nursing diagnoses. Nursing diagnoses in all five cases varied according to the data obtained in the stages one and two. Nursing diagnoses that identified were self-concept problems, such as interference with the role of a wife. This is because one of the treatments for clients of early-stage cervical cancer is the surgical procedure for removing a part or all of the reproductive organs: vaginal, cervical, uterine and ovarian. This affects the reproductive roles and functions of the client, making the client experience self-concept disorders such as body image and roles.

Problems in self-concept have affected clients psychologically and it would affect their quality of life. Quality of life is influenced by the adaptability and personality of the client itself. A healthy personality accompanied by positive views and attitudes towards the health conditions experienced holds an important role in determining the success of treatment.

The efforts to adopt the changes including providing psychosocial support that it can protect clients from stress (Kaplan \& Sudock, 2011). Support could be obtained from family members, such as in the three cases above the client accompanied by a husband, child, and mother. The family, especially the husband, is the closest person to the client and has a close emotional bond that can help clients adapt to the illness. In addition, support could also be provided by health workers, in this case, one of them is a nurse. By providing optimal care it is expected that the client can have a good experience physically, emotionally and spiritually. 
Ida Maryati : The Application of "Roy Adaptation" Theory Model In Women

\section{CONCLUSION}

The use of Roy's conceptual adaptation model is supported by the theory of self-concept and psychosocial support so that care is given comprehensively because in addition to paying attention to physical aspects but also psychological and spiritual aspects so that it is expected that the care provided can improve the quality of life for early cancer patients.

The first stage of assessment for early-stage cervical cancer clients is focused on four modes of adaptation that include physiological modes, self-concept, role function, and interdependence. Then proceed with the second stage of assessment. In the first and second stages of assessment, similar nursing diagnoses are found, but there are several diagnoses only occur in certain respondents. This is in accordance with the nursing paradigm which views clients as unique creatures where there is a possibility of different body responses in facing the same stimulus.

\section{REFERENCES}

Bhattacharjee A. (2013). Self-concept of cancer patients: a comparative study. Voice of Research. 2013;1(4):2277-7733.

Durham, R., \& Chapman, L. (2014). Maternal-Newborn Nursing (2 ed.). Philadelphia: Davis Plus

Kaplan, H.I \& Sudock, B.J. (2011). Synopsis of Psychiatry. New York: Williams and Wilkins Kemenkes RI. (2015). Situasi penyakit Kanker. Jakarta.

Li, C., C, Chen, M., L, Chang, T., C, Chou, H., H, and Chen, M., Y. (2015). Social support buffers the effect of self-esteem on quality of life of early-stage cervical cancer survivors in Taiwan. Eur J Oncol Nurs 2015;19(5):486-494. 
Ida Maryati : The Application of "Roy Adaptation" Theory Model In Women

Rahardjo, Susilo \& Gudnanto.(2011). Pemahaman Individu Teknik Non-Tes. Kudus: Nora Media Enterprise

Roy, C., and Andrews, 2008. The Roy Adaptation Model. Pearson Prentice Hall 